\title{
Effect of adhesive interlining on the creep behavior of woven fabric under low stress in the bias direction
}

\author{
Masayuki Takatera, Ken Ishizawa, KyoungOk Kim
}

\begin{abstract}
${ }^{1}$ Division of Kansei and Fashion Engineering, Institute for Fiber Engineering (IFES), Interdisciplinary Cluster for Cutting Edge Research (ICCER), Shinshu University, Japan

${ }^{2}$ Division of Textile \& Kansei Engineering, Graduate School of Science and Technology, Shinshu University, Japan
\end{abstract}

\author{
kimko@shinshu-u.ac.jp
}

\begin{abstract}
The effect of adhesive interlining on the creep behavior of a woven fabric in the bias direction was investigated. Three-element viscoelastic models were used to approximate the creep behavior of a face fabric and adhesive interlining. The creep model of a laminated fabric comprised a six-element model connected in parallel with the three-element model. Creep tests were carried out using face fabrics, adhesive interlinings, and their laminated fabrics without and with bonding adhesive interlining by hanging samples in the $45^{\circ}$ bias direction under their own weight for 7 days. Creep strains of face fabrics bonded with adhesive interlining were found to be weaker than those of the face fabrics. The creep behavior for the face and interlining fabrics could be approximated using the three-element viscoelastic model with appropriate parameters. The experimental creep behavior of a laminated fabric without bonding was similar to the experimental behavior. However, the experimental creep of laminated fabrics with bonding interlining was less than the calculated creep owing to the increase in stiffness due to the adhesive. By revising the six-element model with the strains just after hanging and for 2 days, it was possible to predict the creep strain over 7 days.
\end{abstract}

\section{Introduction}

For woven fabrics, a direction oblique to the warp and weft is referred to a bias direction. Crossing yarns in the bias direction of fabric are more easily deformed than those in the yarn direction [1-3]. Bias-cut fabric is able to give a soft look and drape, and is thus usually used for a flared skirt or dress. Bias-cut fabric is also partly used for a circular skirt [1]. However, when we store clothing constructed from bias-cut fabric by hanging, the clothing goes out of shape owing to greater fabric strain under the clothing's own weight. There is thus a need for the prediction and prevention of this loss of shape. Gradual deformation under a constant load such as clothing's own weight is called creep. In this study, we investigated the creep behavior of fabric in the bias direction due to the fabric's own weight.

In the manufacturing of clothing, interlining is used to keep the shape of the clothing. Among types of interlining, adhesive interlining, where adhesive is put on the base cloth, is commonly used. Adhesive interlining is fused to the face fabric and maintains the garment form. It is known that mechanical properties of the face fabric such as the bending rigidity and shear stiffness are affected by fusing interlining [4-9]. It is thus necessary to select an appropriate interlining by taking into account these changes. Kim et al. [4-9] studied a method of predicting the bending rigidity and shear stiffness of a laminated fabric comprising an adhesive interlining and face fabric.

Adhesive interlining can affect the creep of a garment. It is necessary to investigate and predict the effects of interlining on fabric creep to select a suitable interlining. The effects and prediction of the creep of interlining in the bias direction have not yet been studied.

There have been several studies on the creep of yarns and fabrics in the yarn direction. Deng et al. [10] investigated the effects of temperature and load on the creep of a polypropylene structure. Milanka et al. [11] measured the creep and recovery of woolen fabric. They classified the entire deformation into elastic deformation, viscoelastic deformation and plastic deformation and obtained the proportions of each. Asayesh et al. [12] investigated the prediction of creep of polyester plain woven fabrics from yarn creep using a three-element viscoelastic model. Urbelis et al. [13] carried out a creep test on laminated fabrics with and without fusing and its component fabrics in the yarn direction. They found that the effect of adhesive on the creep behavior of laminated fabric in the yarn direction is negligible. They introduced a viscoelastic model for the creep and creep recovery behavior of a fabric and determined the parameters of the model, for a relatively short time of 30 min and a large 
load of 40-50 N, in the yarn direction [14]. They also calculated the redistribution of tension for each fabric without fusing under a constant load [15]. However, there has been no investigation of the creep of laminated fabric in the bias direction. Deformation of fabric in the bias direction is larger than one of yarn directions. In addition, there is a large adhesive effect on the rigidity of laminated fabric in shear that cannot be neglected $[8,9]$.

In the present study, to clarify the effect of adhesive interlining on the creep behavior of laminated fabric, we investigated the creep of laminated fabric and its components in the $45^{\circ}$ bias direction under the fabric's own weight. Creep of the face fabric and adhesive interlining was approximated using a three-element viscoelastic model. Creep for laminated fabric was then expressed using a six-element model that was connected in parallel with the threeelement model and the modeled creep behavior was compared with the experimentally observed behavior.

\section{Methods and materials}

\section{Analytical approach}

In this study, we employ a viscoelastic model for a single fabric using a three-element model that reveals creep behavior. The model is represented as a Voigt model and a spring connected in series as shown in Fig. 1. Here, $K_{1}$, $K_{2}, K_{3}$ and $K_{4}$ are the elastic moduli per unit width $\left(\mathrm{Ncm}^{-1}\right)$ of the different springs, $y_{1}$ and $y_{2}$ are the viscosity coefficients per unit width $\left(\mathrm{Ncm}^{-1} \mathrm{~s}\right)$ of the dash pots, and $F_{1}$ and $F_{2}$ are the applied load per unit width $\left(\mathrm{Ncm}^{-1}\right) . \varepsilon_{f}$ and $\varepsilon_{i}$ are the stains of each three element model.

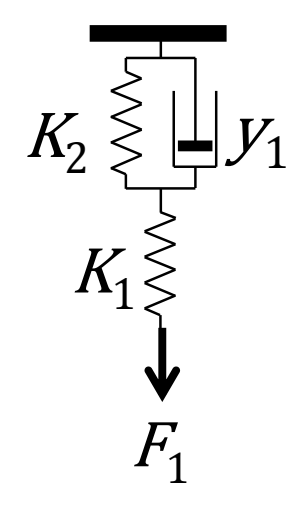

Fig. 1. Three-element models

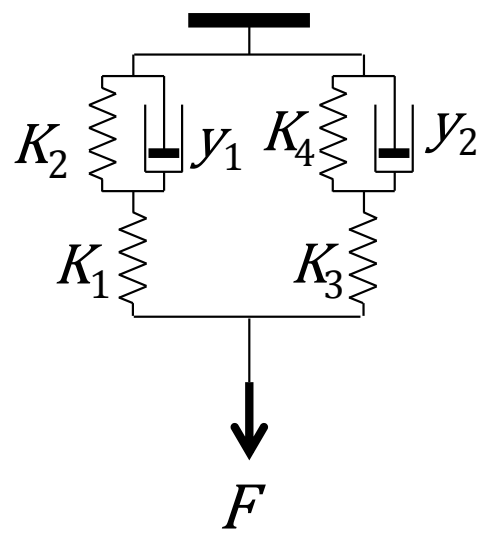

Fig. 2. Six-element model

We denote time by $t$ and obtain the strain of a fabric named fabric1, $\varepsilon_{f}$, as

$\varepsilon_{f}=\frac{F_{1}}{K_{1}}+\frac{F_{1}}{K_{2}}\left(1-e^{-\frac{K_{2}}{y_{1}} t}\right)$.

The strain of another fabric named fabric $2, \varepsilon_{i}$, is expressed as

$\varepsilon_{f}=\frac{F_{2}}{K_{3}}+\frac{F_{2}}{K_{4}}\left(1-e^{-\frac{K_{4}}{y_{2}} t}\right)$.

When we ignored the effect of the adhesive, the laminated fabric can then be expressed by a six-element model connected in parallel with a three-element model as shown in Fig. 2. Urbelis et al. [15] proposed a six-element model by connecting two three-element models in series. Their model is equivalent to the six-element model in Fig. 2 [17]. However, the composition of viscoelastic constants in solution of the equation is unknown. For the sixelement model which connected models of equation (1) and equation (2) in parallel, we set the strain and total force of the six-element model as $\varepsilon$ and $F$, and express first and second - order differentiations of strains and forces with respect to $t$ by dot such as $\dot{\varepsilon}$ and $\ddot{\varepsilon}$, and $\dot{F}$ and $\ddot{F}$. From the relations of the force and strain, we obtain following relations;

$F=F_{1}+F_{2}$,

$F_{1}=K_{1} \varepsilon_{K 1}=K_{2} \varepsilon_{V 1}+y_{1} \dot{\varepsilon}_{V 1}$

$F_{2}=K_{3} \varepsilon_{K 3}=K_{4} \varepsilon_{V 2}+y_{2} \dot{\varepsilon}_{V 2}$

$\varepsilon=\varepsilon_{i}=\varepsilon_{K 1}+\varepsilon_{V 1}=\varepsilon_{f}=\varepsilon_{K 3}+\varepsilon_{V 2}$,

where $\varepsilon_{K 1}$ and $\varepsilon_{K 3}$ are strain of spring $K_{1}$ and $K_{3}, \varepsilon_{V 1}$ and $\varepsilon_{V 2}$ are strain of Voigt models for fabric1 and fabric $2, \dot{\varepsilon}_{V 1}$ and $\dot{\varepsilon}_{V 2}$ are those differentiation with respect to $t$. 
After eliminating $\varepsilon_{K 1}, \varepsilon_{K 3}, \quad \varepsilon_{V 1}, \quad \varepsilon_{V 2}, \dot{\varepsilon}_{V 1}, \dot{\varepsilon}_{V 2}, F_{1}$, and $F_{2}$ from simultaneous equations (3)-(6), using load conditions

$\dot{F}=\ddot{F}=0$,

we obtain the constitutive equation

$\ddot{\varepsilon}+g \dot{\varepsilon}+h \varepsilon=d$,

where $g, h$ and $d$ are constants given by following equations.

$g=\frac{G K_{3}\left(y_{1}+y_{2}\right)+H y_{2}\left(K_{1}+K_{3}\right)+D\left(K_{3} K_{4}+\frac{K_{1} K_{2} y_{2}}{y_{1}}\right)}{D y_{2}\left(K_{1}+K_{3}\right)}$,

$h=\frac{G K_{3}\left(K_{2}+K_{4}\right)+H\left(K_{3} K_{4}+\frac{K_{1} K_{2} y_{2}}{y_{1}}\right)}{D y_{2}\left(K_{1}+K_{3}\right)}$,

$d=\frac{(G+H)\left(K_{3}+K_{4}\right)}{D y_{2}\left(K_{1}+K_{3}\right)} F$,

where $G, H$ and $D$ are constants given by as following equations.

$G=\frac{K_{1}\left(K_{1}+K_{2}\right) y_{2}}{y_{1}}-K_{1}\left(K_{3}+K_{4}\right)$

$H=K_{1} K_{4}-K_{2} K_{3}$

$D=K_{1} y_{2}-K_{3} y_{1}$

The solution of Equation (8) is

$\varepsilon=C_{1} \exp \left(\lambda_{1} t\right)+C_{2} \exp \left(\lambda_{2} t\right)+C_{3}$,

where

$\left\{\begin{array}{l}\lambda_{1}=\frac{-g+\sqrt{g^{2}-4 h}}{2} \\ \lambda_{2}=\frac{-g-\sqrt{g^{2}-4 h}}{2}\end{array}\right.$.

Here, the integration constant $C_{3}$ is determined by the conditions of $\lambda_{1}$ and $\lambda_{2}$ for an appropriate solution:

$C_{3}=\frac{d}{h}$.

$C_{1}$ and $C_{2}$ need to be determined. Thus, as initial conditions, the strain and strain rate at time $t=0$ are defined as $\left.\varepsilon\right|_{t=0}$ and $\left.\dot{\varepsilon}\right|_{t=0}$ respectively. When $t=0$, only the springs having elastic moduli $K_{1}$ and $K_{4}$ are deformed. Thus, $\left.\varepsilon\right|_{t=0}$ can be expressed as

$\left.\varepsilon\right|_{t=0}=\frac{F_{1}}{K_{1}+K_{3}}$.

Here, $\left.\dot{\varepsilon}\right|_{t=0}$ is not affected by $K_{2}$ or $K_{4}$ because they do not change at $t=0$. We thus derive $\left.\dot{\varepsilon}\right|_{t=0}$ using a four-element model excluding $K_{2}$ and $K_{4}$ :

$\left.\dot{\varepsilon}\right|_{t=0}=\frac{F}{K_{1}}\left(\frac{K_{1}}{K_{1}+K_{3}}-\frac{y_{1}}{y_{1}+y_{2}}\right)\left(-\frac{\frac{1}{y_{1}}+\frac{1}{y_{2}}}{\frac{1}{K_{1}}+\frac{1}{K_{3}}}\right)+\frac{K_{1} F}{y_{1}\left(K_{1}+K_{3}\right)}$.

We then obtain

$C_{1}=\frac{\left.\dot{\varepsilon}\right|_{t=0}+\left(\frac{d}{h}-\left.\varepsilon\right|_{t=0}\right) \lambda_{2}}{\lambda_{1}-\lambda_{2}}$,

$C_{2}=\left.\varepsilon\right|_{t=0}-\frac{d}{h}-C_{1}$.

If we can obtain parameters of the three-element model in a creep test of each component fabric, we can then predict the creep behavior of the laminated fabric without fusing using equation (15).

\section{Experimental approach}

We measured creep strains of the face fabric, adhesive interlining, lamination of both fabrics without fusing 
(hereinafter referred to as overlapped fabric) and lamination of both fabrics with fusing (hereinafter referred to as fused fabric) in the $45^{\circ}$ bias direction. The load was set as the self-weight of an $80 \mathrm{~cm}$ length of each fabric assuming a dress of knee length. Adhesive interlining of dot type was used.

A fabric sample and the creep test method are shown in Fig. 3. The sample was hung on a wall by fixing the upper end with a magnetic bar. Dimensions of samples were measured before hanging. The sample fabrics were cut on the $45^{\circ}$ bias. The shape was a long rectangle with width of $5 \mathrm{~cm}$ as shown in Fig. 3. It was not possible to make an $80 \mathrm{~cm}$ length of fabric in the bias direction without a seam owing to the fabric size. Thus, the same fabric was sewn to make an $80 \mathrm{~cm}$ length of fabric. Sewing yarn of polyester was used. The load is very small so it was neglected. Gauge lines were drawn at $10 \mathrm{~cm}$ intervals and the initial gauge length was measured before hanging. The weight of the length of $80 \mathrm{~cm}$ was applied to the centerline of the gauge. In addition, to avoid restriction by fixing with a magnet at the top and by sewing at the bottom of the gauge, $15 \mathrm{~cm}$ spacings were set at the top and bottom of the gauge lines. The details of experiment are shown in Fig. 4.

The length between the gauge lines was measured as shown in Fig. 3. To measure the exact length between gauge lines, we made holes with diameters of $0.9 \mathrm{~mm}$ in the width-wise center of the gauge lines. The length between the gauge lines was then recorded by making a dot with a marker on the opposite side of a polyethylene terephthalate film through the holes. The dots on the film were then scanned using a flatbed scanner, and the length was obtained from the number of pixels. The scan resolution was $600 \mathrm{dpi}$. It means that the maximum accuracy is $0.04 \mathrm{~mm}$ without experimental error. There was large deformation of clothing in the bias direction during 7 days of hanging [1]. Measurements were thus made at 1 day intervals for 7 days. Five sheets per one kind of fabric were prepared and average values were used in the analysis. For one sheet, we measured strains twice and took the average. The conditions of the experimental environment were a temperature of $20 \pm 1{ }^{\circ} \mathrm{C}$ and relative humidity of $65 \pm 5 \%$.

Adhesive interlining was fused by a press machine. The pressing temperature was $150{ }^{\circ} \mathrm{C}$, the pressure was $9.4 \mathrm{kPa}$, and the pressing time was $10 \mathrm{~s}$. When fusing interlining to the face fabric, pressing affected both the adhesive interlining and face fabric. To ensure the same condition for each fabric, the pressing treatment was carried out for the sample without fusing. The press treatment method for each sample is listed in Table 1. In table 1, overlapped face fabric and adhesive interlining was marked as "Face fabric || adhesive interlining". In addition, laminated face fabric and adhesive interlining was marked as "Face fabric $\mid$ adhesive interlining". Overlapped fabric was made by fixing face fabric and adhesive interlining with yarn knots at eight places on gauge lines.

Three wool face fabrics of different weave and two adhesive interlinings of different adhesive mass were used. Tables 2 and 3 give the specifications of experimental samples. There were six combinations of face fabrics and adhesive interlinings. Table 4 gives the combinations, sample designations and applied loads of the $80 \mathrm{~cm}$ length weight.

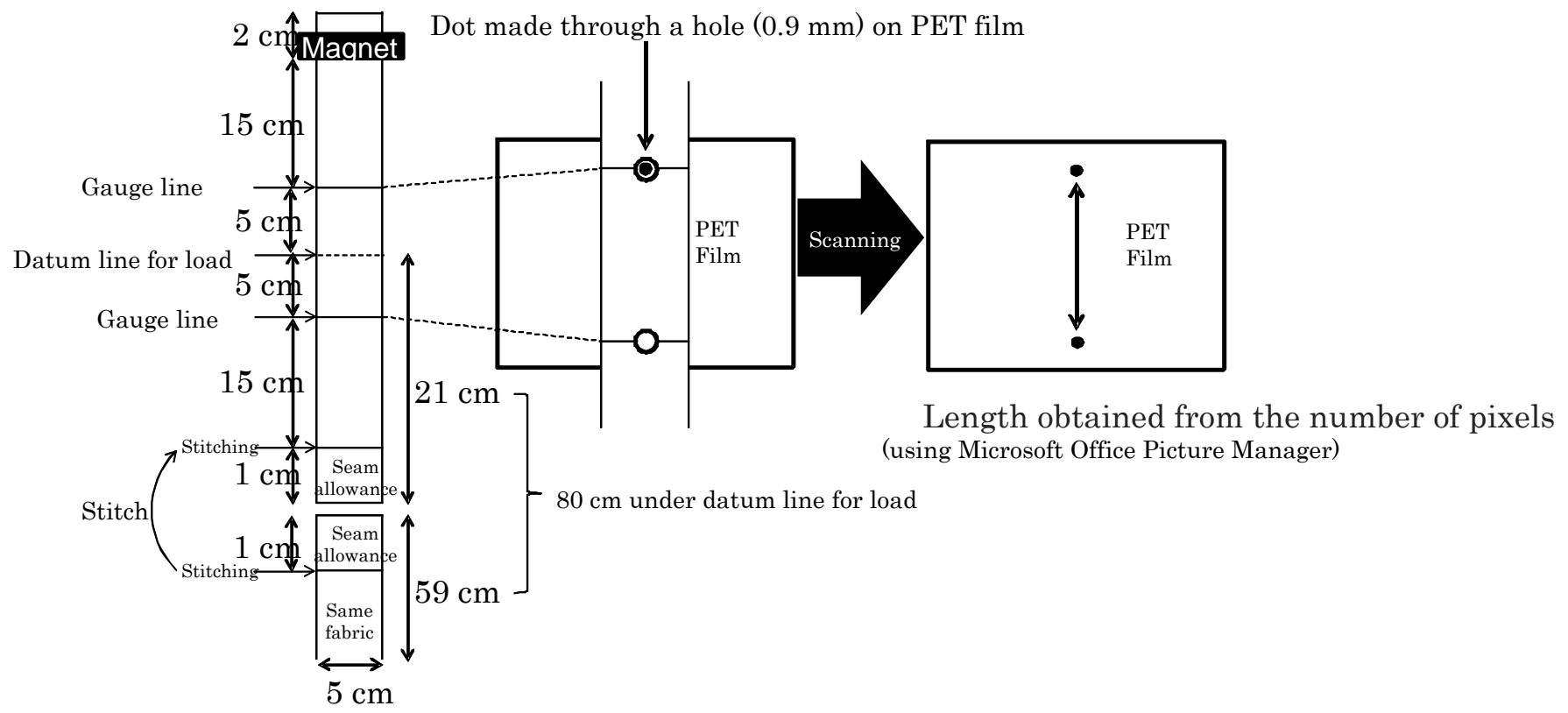

Fig. 3. Experimental method 


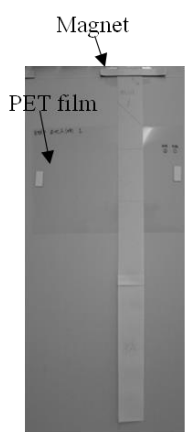

(a) $80 \mathrm{~cm}$ sample hung on a wall

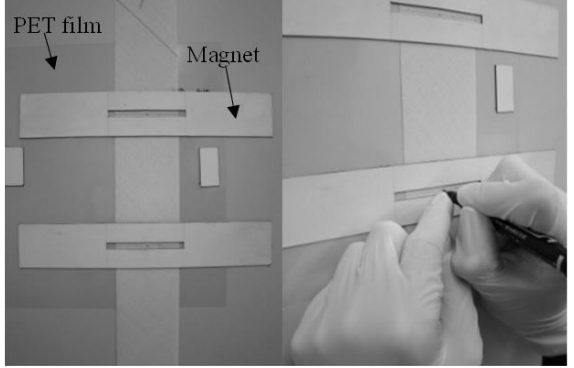

(b) marking a dot on PET film

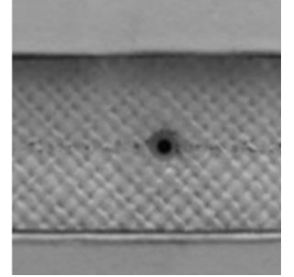

(c) a hole $(0.9 \mathrm{~mm})$ on sample

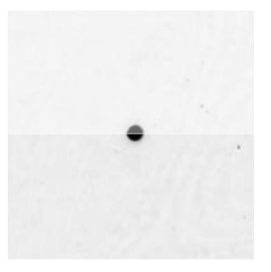

(d) scanned PTFE film being marked

Fig. 4 Detail of experiment

There are two $45^{\circ}$ bias directions - one where the warp is rotated clockwise (cw) and one where the warp is rotated counter clockwise (ccw). The shear stiffness of the face fabric was measured for both directions using a KES-FB1 shear tester (Katotech Co., Ltd., Kyoto, Japan) [18] and the direction having the lower stiffness which will show larger deformation was adopted. The five sheets were measured and the average value taken. The shear stiffness of the face fabric is given in Table 2.

Parameters $K_{1}$ and $K_{3}$ were determined from the load and strain at $t=0 . K_{2}$ and $y_{1}$ of the face fabric and $E_{2}$ and $y_{2}$ of the adhesive interlining were determined by fitting experimental and model strains with the three-element model using Excel Solver (Microsoft). $K_{2}, K_{4}, y_{1}$ and $y_{2}$ were set to obtain the smallest difference of the square sum between experimental and calculated values for each fabric. Creep behaviours of fused fabric and overlapped fabric were calculated using equation (15) of the six-element model substituting the obtained parameters. The calculated creep and experimental creep were compared.

Table 1 Pressing method for each sample

\begin{tabular}{|l|l|}
\hline Experimental sample & Pressing method \\
\hline Face fabric & Pressing alone \\
\hline Adhesive interlining & Pressing with PTFE film and then removing film \\
\hline $\begin{array}{l}\text { Overlapped fabric } \\
\text { (Face fabric || adhesive } \\
\text { interlining ) }\end{array}$ & Pressing face fabric and adhesive interlining separately \\
\hline $\begin{array}{l}\text { Fused fabric } \\
\text { (Face fabric | adhesive } \\
\text { interlining ) }\end{array}$ & Laminating face fabric and adhesive interlining by pressing \\
\hline
\end{tabular}

Table 2 Specifications of the face fabric

\begin{tabular}{|c|c|c|c|c|c|c|c|}
\hline \multirow{2}{*}{$\begin{array}{l}\text { Face } \\
\text { fabric }\end{array}$} & \multicolumn{2}{|c|}{ Shear stiffness (cN/cm×degree) } & \multirow[t]{2}{*}{ Material } & \multirow{2}{*}{$\begin{array}{l}\text { Weave } \\
\text { structure }\end{array}$} & \multirow{2}{*}{$\begin{array}{l}\text { Area } \\
\text { density } \\
{\left[\mathrm{g} / \mathrm{m}^{2}\right]}\end{array}$} & \multirow{2}{*}{$\begin{array}{l}\text { Yarn count } \\
\text { [tex] } \\
(\text { warp } \times \text { weft) }\end{array}$} & \multirow{2}{*}{$\begin{array}{l}\text { Weave } \\
\text { density }[/ \mathrm{cm}] \\
(\text { warp } \times \text { weft })\end{array}$} \\
\hline & $\begin{array}{l}\text { Clockwise } \\
\text { rotation }(\mathrm{cw}) *\end{array}$ & $\begin{array}{l}\text { Counter clockwise } \\
\text { rotation }(\mathrm{ccw}) *\end{array}$ & & & & & \\
\hline A & 0.625 & 0.641 & $\begin{array}{l}\text { Wool } \\
100 \%\end{array}$ & Plain & 134.3 & $26.3 \times 23.3$ & $25.8 \times 23.4$ \\
\hline B & 0.662 & 0.647 & wool $100 \%$ & Twill & 192.4 & $31.0 \times 22.6$ & $35.6 \times 25.8$ \\
\hline $\mathrm{C}$ & 0.655 & 0.660 & wool $100 \%$ & Satin & 217.9 & $30.1 \times 28.9$ & $38.4 \times 25.6$ \\
\hline
\end{tabular}

* Rotation direction of warp when observed from the face side

Table 3 Specifications of the adhesive interlining

\begin{tabular}{|l|l|l|l|l|l|l|l|}
\hline $\begin{array}{l}\text { Adhesive } \\
\text { interlining }\end{array}$ & $\begin{array}{l}\text { Material(textile/ } \\
\text { adhesive) }\end{array}$ & $\begin{array}{l}\text { Weave } \\
\text { structure }\end{array}$ & $\begin{array}{l}\text { Area } \\
\text { density } \\
{\left[\mathrm{g} / \mathrm{m}^{2}\right]}\end{array}$ & $\begin{array}{l}\text { Yarn count } \\
{[\text { tex }]} \\
(\text { warp } \times \text { weft })\end{array}$ & $\begin{array}{l}\text { Weave } \\
\text { density } \\
{[/ \mathrm{cm}]} \\
(\mathrm{warp} \times \text { weft })\end{array}$ & $\begin{array}{l}\text { Adhesive dot } \\
\text { density } \\
{\left[/ \mathrm{cm}^{2}\right]} \\
(\mathrm{warp} \times \text { weft })\end{array}$ & $\begin{array}{l}\text { Adhesive } \\
\text { mass } \\
{\left[\mathrm{g} / \mathrm{m}^{2}\right]}\end{array}$ \\
\cline { 1 - 2 } & $\begin{array}{l}\text { Polyester 100\%/ } \\
\text { dot type of } \\
\text { polyamide }\end{array}$ & & 38.5 & $3.0 \times 3.0$ & $38.6 \times 24.4$ & 82 & 8.7 \\
\cline { 1 - 2 } & & 39.9 & & & 105 & 10.0 \\
\hline
\end{tabular}


Table 4 Combinations of the face fabric and interlining, designations of the experimental samples and sizes of load

\begin{tabular}{|c|c|c|c|c|c|c|}
\hline \multicolumn{3}{|c|}{ Combination } & \multirow[b]{2}{*}{$\begin{array}{l}\text { Shear direction } \\
\text { in experiment }\end{array}$} & \multicolumn{3}{|c|}{ Load [cN/cm] (length: $80 \mathrm{~cm})$} \\
\hline $\begin{array}{c}\text { Num } \\
\text { ber }\end{array}$ & $\begin{array}{l}\text { Face } \\
\text { fabric }\end{array}$ & $\begin{array}{l}\text { Adhesive } \\
\text { interlining }\end{array}$ & & Face fabric & $\begin{array}{l}\text { Adhesive } \\
\text { interlining }\end{array}$ & $\begin{array}{l}\text { Overlapped fabric } \\
\text { and laminated fabric }\end{array}$ \\
\hline 1 & A & \multirow{3}{*}{$\mathrm{a}$} & $\mathrm{cW}$ & 1.053 & \multirow{3}{*}{0.302} & 1.355 \\
\hline 2 & $\mathrm{~B}$ & & $\mathrm{ccw}$ & 1.509 & & 1.811 \\
\hline 3 & $\mathrm{C}$ & & $\mathrm{cW}$ & 1.709 & & 2.011 \\
\hline 4 & A & \multirow{3}{*}{ b } & $\mathrm{cW}$ & 1.053 & \multirow{3}{*}{0.312} & 1.366 \\
\hline 5 & $\mathrm{~B}$ & & $\mathrm{ccW}$ & 1.509 & & 1.822 \\
\hline 6 & $\mathrm{C}$ & & $\mathrm{cW}$ & 1.709 & & 2.022 \\
\hline
\end{tabular}

\section{Results and Discussion}

\section{Creep strains of samples}

Figures 5-10 present the strain versus time for all samples and their combinations. For the $45^{\circ}$ bias direction of the face fabric and adhesive interlining, it was found that creep occurs under the fabric weight of a length of 80 $\mathrm{cm}$. Strain changes of the face fabric were greater than those of the adhesive interlining. The small strain changes of the interlining were due to the low weight of the interlining. Overlapped fabrics had strain intermediate of the strains of their two components. However, strains of fused fabrics of all combinations were lower than those of overlapped fabrics.

Table 5 gives the variation percentage of strain of laminated fabric after 7 days. The variation was obtained as

$(($ Strain of fused or overlapped fabric - Strain of face fabric $) \times 100) /$ Strain of face fabric.

The variation for the overlapped fabric was from $-20 \%$ to $-44.7 \%$ while that of the fused fabric was from $-63.4 \%$ to $-75.4 \%$.

Urbelis [13] described how the effect of fusing on the creep behavior of a fused fabric in the yarn direction would be negligible. However, in the bias direction, the present study found that the effect of adhesive is not negligible.

It was thus confirmed that fusing adhesive interlining to a face fabric reduces the creep strain of the face fabric. The strain changes of fused fabrics are small owing to the restraint of deformation by adhesive on the face fabric.

\section{Prediction of creep strains of laminated and overlapped fabrics using three-element models}

Table 6 gives constants and equations for the three-element model of each combination. Strains of the face fabric and interlining approximated using three-element models are shown in Figs. 5-10. Approximated strains of the face fabric and adhesive interlining obtained with the three-element model are in good agreement with experimental values. It was thus found that creep behavior due to the fabric's own weight in the $45^{\circ}$ bias direction can be approximated using the three-element model.

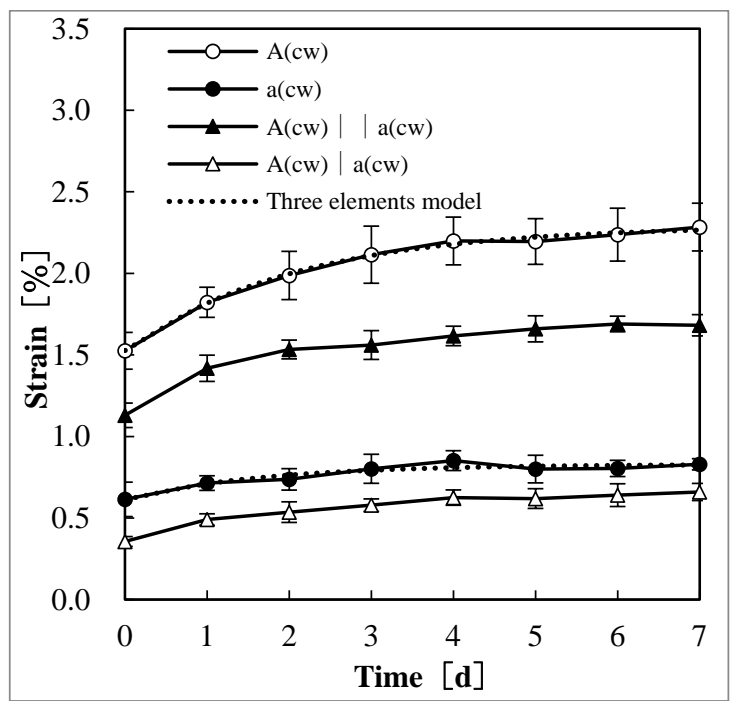

Fig. 5. Strain change with time (Combination $1(\mathrm{~A}-\mathrm{a})$ )

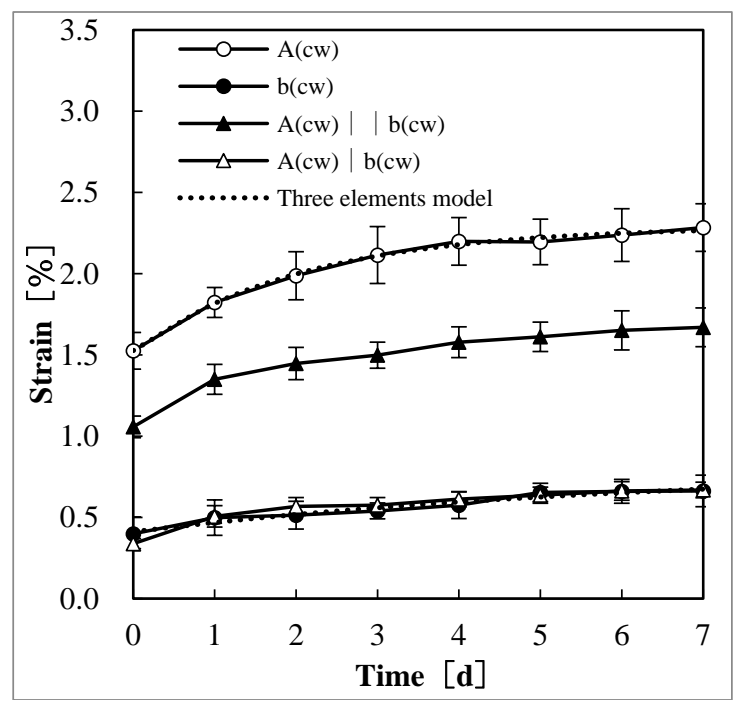

Fig. 6 Strain change with time (Combination $2(\mathrm{~A}-\mathrm{b})$ ) 

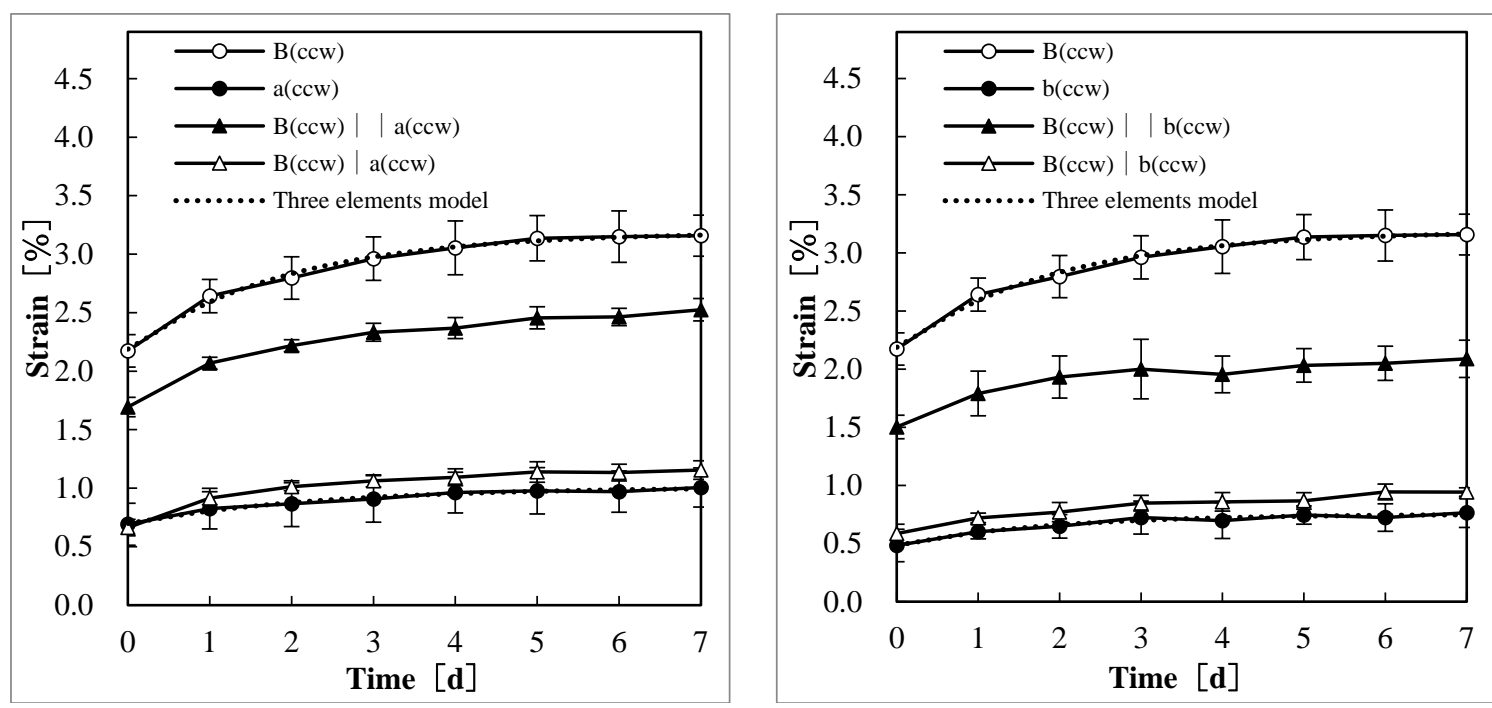

Fig. 7 Strain change with time (Combination $3(B-a))$ Fig. 8. Strain change with time (Combination $4(B-b)$ )
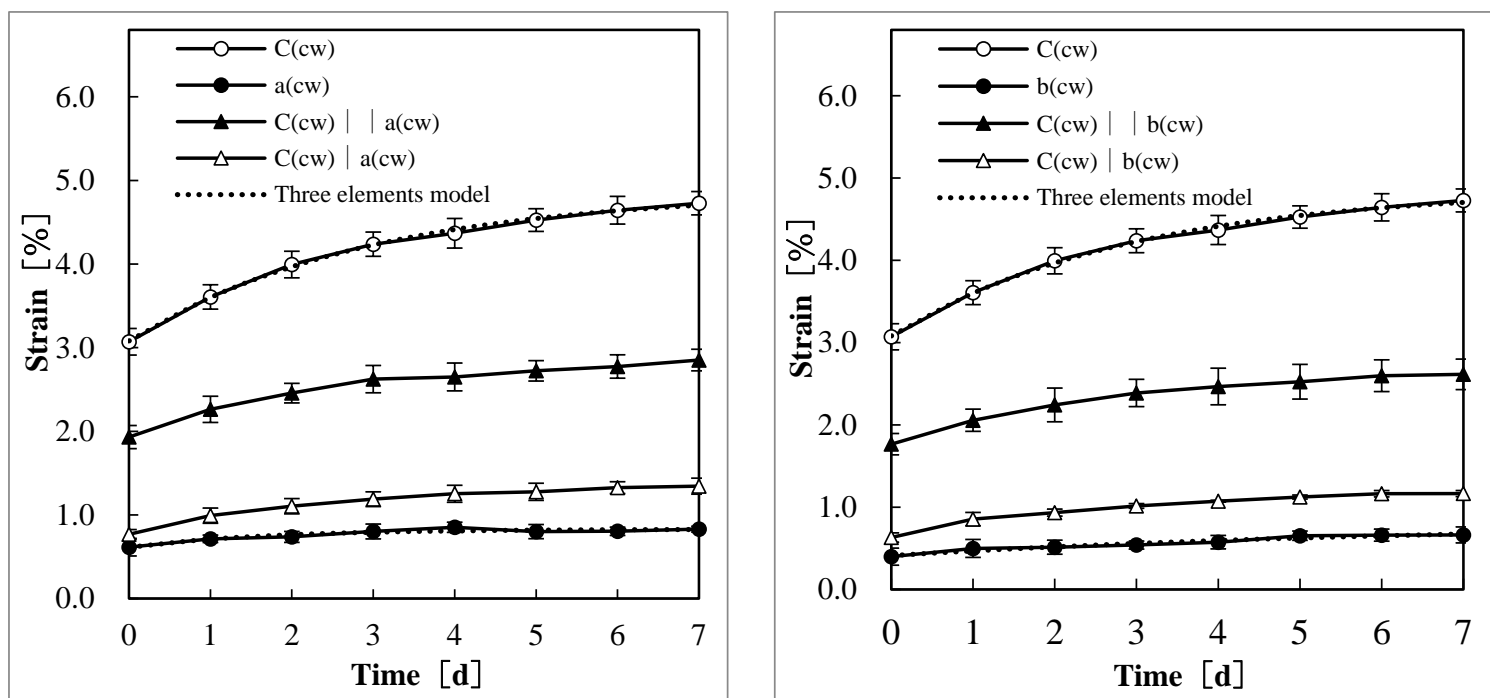

Fig. 9. Strain change with time (Combination $5(\mathrm{C}-\mathrm{a})$ )

Fig. 10 Strain change with time (Combination $6(\mathrm{C}-\mathrm{b}))$

Table 5 Variation of strain of laminated fabric after 7 days

\begin{tabular}{|c|c|c|c|}
\hline Combination & Variation (\%) & Combination & Variation (\%) \\
\hline $\mathrm{A}|| \mathrm{a}$ & -26.4 & $\mathrm{~A} \mid \mathrm{a}$ & -71.1 \\
\hline $\mathrm{A} \mid \mathrm{b}$ & -26.9 & $\mathrm{~A} \mid \mathrm{b}$ & -70.7 \\
\hline $\mathrm{B}|| \mathrm{a}$ & -20.0 & $\mathrm{~B} \mid \mathrm{a}$ & -63.4 \\
\hline $\mathrm{B}|| \mathrm{b}$ & -33.8 & $\mathrm{~B} \mid \mathrm{b}$ & -70.1 \\
\hline $\mathrm{C} \mid \mathrm{a}$ & -39.7 & $\mathrm{C} \mid \mathrm{a}$ & -71.6 \\
\hline $\mathrm{C}|| \mathrm{b}$ & -44.7 & $\mathrm{C} \mid \mathrm{b}$ & -75.4 \\
\hline
\end{tabular}

Table 6 Constants and equations for the three-element model

\begin{tabular}{|l|l|l|l|l|l|c|}
\hline \multicolumn{2}{|c|}{ Constant } & $\begin{array}{c}F_{1} \\
{[\mathrm{cN} / \mathrm{cm}]}\end{array}$ & $\begin{array}{c}K_{1} \\
{[\mathrm{cN} / \mathrm{cm}]}\end{array}$ & $\begin{array}{c}K_{2} \\
{[\mathrm{cN} / \mathrm{cm}]}\end{array}$ & $\begin{array}{c}y_{1} \\
{[\mathrm{cN} / \mathrm{cm}]}\end{array}$ & Equation for $\varepsilon[\%]$ \\
\hline Face fabric & $\mathrm{A}$ & 1.053 & 68.9 & 137.5 & 288.8 & $\varepsilon=2.293-0.766 e^{-0.476 t}$ \\
\cline { 2 - 7 } & $\mathrm{B}$ & 1.509 & 68.9 & 150.7 & 292.6 & $\varepsilon=3.190-1.002 e^{-0.515 t}$ \\
\cline { 2 - 7 } & $\mathrm{C}$ & 1.709 & 55.5 & 95.8 & 278.9 & $\varepsilon=4.864-1.784 e^{-0.344 t}$ \\
\hline $\begin{array}{l}\text { Sample } \\
\text { S Constant }\end{array}$ & $\begin{array}{c}F_{2} \\
{[\mathrm{cN} / \mathrm{cm}]}\end{array}$ & $\begin{array}{c}K_{3} \\
{[\mathrm{cN} / \mathrm{cm}]}\end{array}$ & $\begin{array}{c}K_{4} \\
{[\mathrm{cN} / \mathrm{cm}]}\end{array}$ & $\begin{array}{c}y_{2} \\
{[\mathrm{cN} / \mathrm{cm}]}\end{array}$ & Equation for $\varepsilon[\%]$ \\
\hline $\begin{array}{l}\text { Adhesive } \\
\text { interlining }\end{array}$ & $\mathrm{a}$ & 0.302 & 49.2 & 140.0 & 235.2 & $\varepsilon=0.829-0.216 e^{-0.596 t}$ \\
\cline { 2 - 7 } & $\mathrm{b}$ & 0.313 & 76.0 & 79.2 & 507.6 & $\varepsilon=0.806-0.395 e^{-0.156 t}$ \\
\hline
\end{tabular}




\section{Prediction of creep strains of laminated fabrics using six-element models}

The strain of each combination was calculated with the six-element model using parameters of each component fabric. Experimental and calculated strains are compared in Figs. 11-16. Strains calculated using the six-element model were similar to the experimental strains of overlapped fabric. The equation for the six-element model and the error in the predicted strain after 7 days are presented in Table 7 . The error was calculated as

(Calculated value - Experimental value) $\times 100 /$ (Experimental value)

The differences (i.e., errors) between experimental and calculated values after 7 days ranged from $-2.33 \%$ to $-11.61 \%$. Thus, stains of overlapped fabric could be predicted by the calculated values using the experimental values of the strain of the face fabric and interlining.

As described above, the strain changes of laminated fabric were smaller than those of overlapped fabric. The reason is considered to be the adhesive on the face fabric. Adhesive restrains the deformation of a face fabric in a laminated fabric especially in shear [8,9]. Therefore, if the strain of the face fabric with adhesive can be measured and the creep strain of the face fabric with adhesive can be calculated using the three-element model, it will be possible to predict the strain of the laminated fabric using the six-element model. However, putting adhesive on a face fabric is difficult technique. Therefore, the strain of the face fabric with adhesive was estimated from the experimental results. To estimate the strain with a small number of parameters, a magnification factor $n$ was introduced so that there is agreement between the experimental and calculated strains at $t=0$. So that the calculated value $\left.\varepsilon\right|_{t=0}$ and experimental value $\left.\varepsilon_{\text {exp }}\right|_{t=0}$ agree using $n$, from equation (18), we obtain

$\left.\varepsilon_{\text {exp }}\right|_{t=0}=\frac{F}{n K_{1}+K_{3}}$.

$n$ is calculated as

$n=\frac{1}{K_{1}}\left(\frac{F}{\left.\varepsilon_{\text {exp }}\right|_{t=0}}-K_{3}\right)$.

Parameters $K_{1}, K_{2}$ and $y_{1}$ of the three-element model for the face fabric are then multiplied by $n$. Here, when all three constants are multiplied by $n$, the strain becomes $1 / n$. Thus, the plot of the three-element model is shifted parallel to the original plot. The six-element model revised with $n$ is presented in Table 8. Errors of predicted strains after 7 days are given in Table 8. The calculated behavior of the revised six-element model is shown in Figs. 11-16. The figures show that the strains of the revised six-element model are in good agreement with those of fused fabrics with relatively small errors compared with those before revision as shown in Tables 7 and 8.

Consequently, the strain of laminated fabric can be predicted from the experimental strain of the face fabric and adhesive interlining and the experimental strain of the fused fabric at time zero (immediately after hanging).

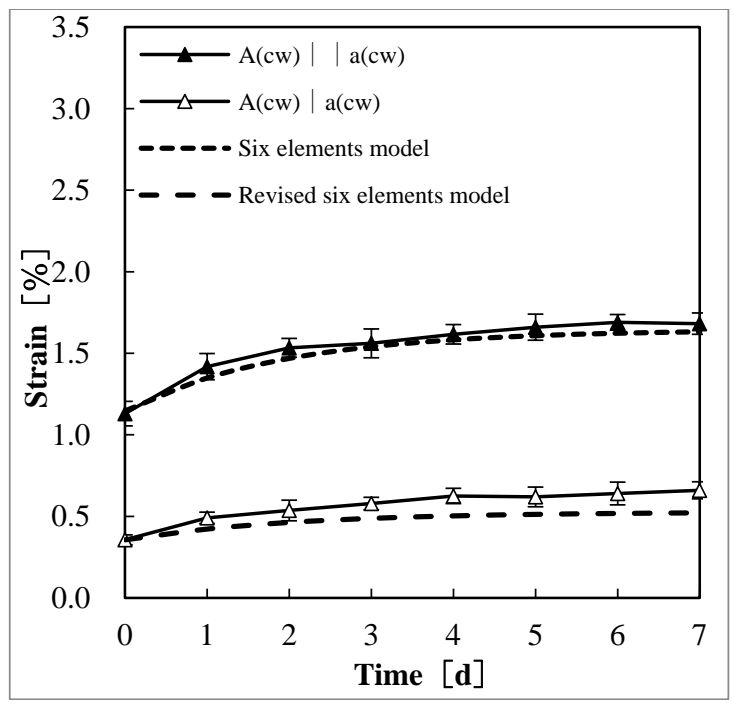

Fig. 11. Comparison of calculated and experiment strains (Combination $1(\mathrm{~A}-\mathrm{a})$ )

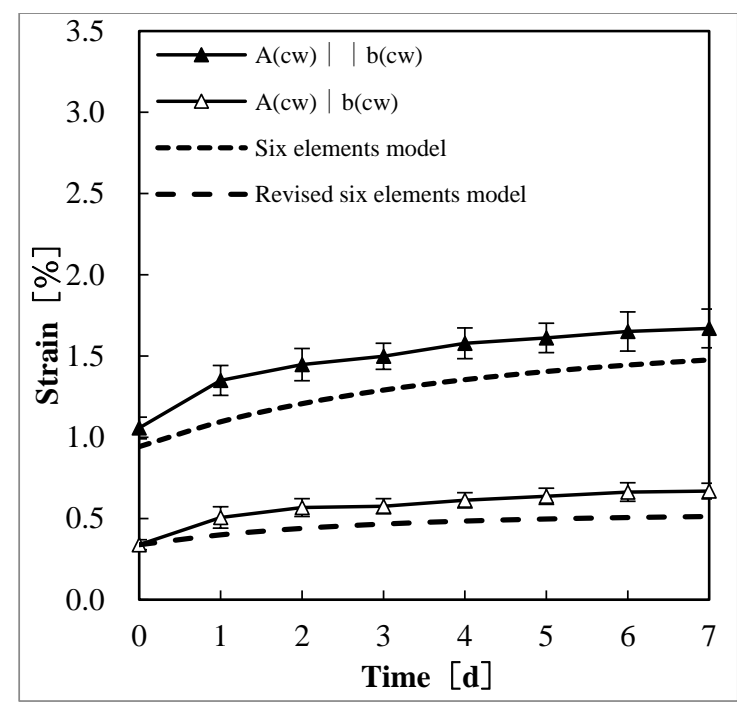

Fig. 12. Comparison of calculated and experiment strains (Combination 1 (A-b)) 


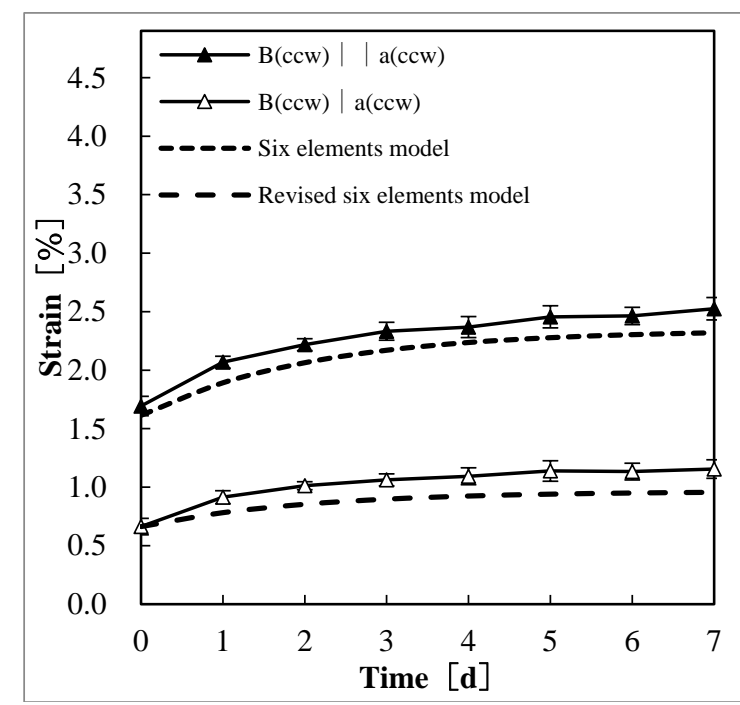

Fig. 13. Comparison of calculated and experiment strains (Combination $1(\mathrm{~B}-\mathrm{a})$ )

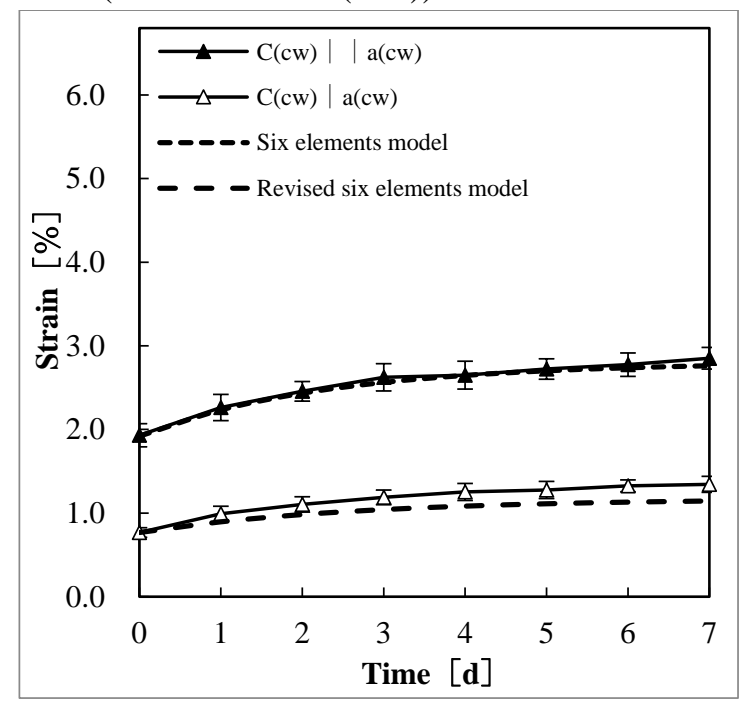

Fig. 15. Comparison of calculated and experiment strains (Combination $1(\mathrm{C}-\mathrm{a})$ )

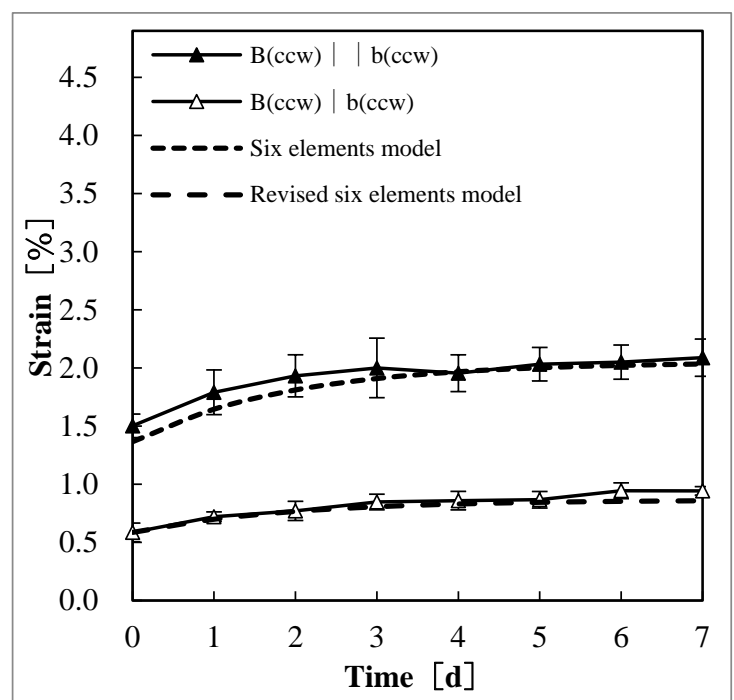

Fig. 14. Comparison of calculated and experiment strains (Combination $1(\mathrm{~B}-\mathrm{b})$ )

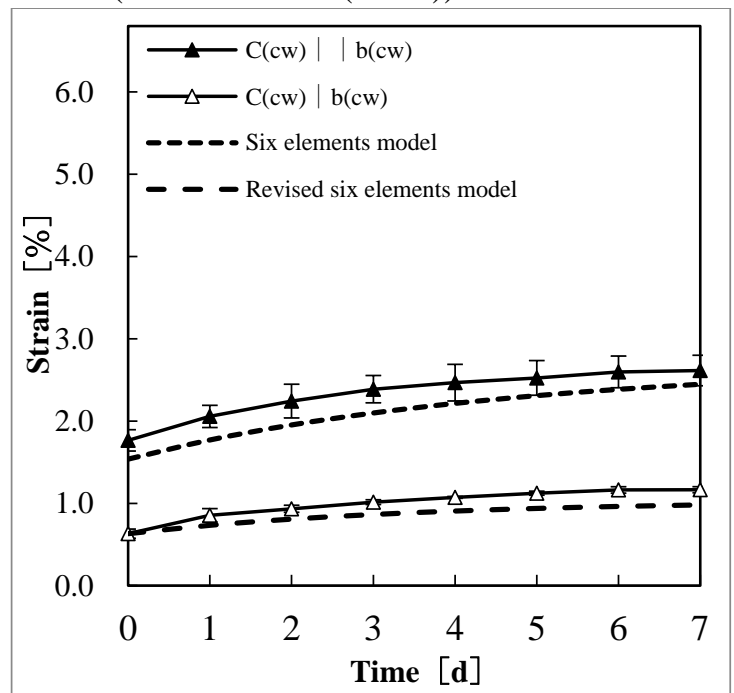

Fig. 16. Comparison of calculated and experiment strains (Combination $1(\mathrm{C}-\mathrm{b})$ )

Table 7 Equations for the six-element model and error in the predicted strain after 7 days

\begin{tabular}{|c|c|c|c|}
\hline \multirow{2}{*}{ Combination } & Equation for six elements model & \multicolumn{2}{|c|}{ Error of predicted strain after 7 days } \\
\cline { 3 - 4 } & $\varepsilon=-0.489 e^{-0.515 t}-0.00962 e^{-0.778 t}+1.645$ & $-2.97 \%$ & fused fabric \\
\hline $1(\mathrm{~A}-\mathrm{a})$ & $\varepsilon=-0.566 e^{-0.205 t}-0.104 e^{-0.624 t}+1.612$ & $-11.6 \%$ & $121 \%$ \\
\hline $2(\mathrm{~A}-\mathrm{b})$ & $\varepsilon=-0.676 e^{-0.462 t}-0.0566 e^{-0.679 t}+2.347$ & $-8.13 \%$ & $101 \%$ \\
\hline $3(\mathrm{~B}-\mathrm{a})$ & $\varepsilon=-0.678 e^{-0.521 t}-0.00832 e^{-0.789 t}+2.052$ & $-2.61 \%$ & $116 \%$ \\
\hline $4(\mathrm{~B}-\mathrm{b})$ & $\varepsilon=-0.792 e^{-0.403 t}-0.0979 e^{-0.741 t}+2.810$ & $-3.15 \%$ & $106 \%$ \\
\hline $5(\mathrm{C}-\mathrm{a})$ & $\varepsilon=-1.087 e^{-0.192 t}-0.110 e^{-0.486 t}+2.735$ & $-6.37 \%$ & $110 \%$ \\
\hline $6(\mathrm{C}-\mathrm{b})$ & &
\end{tabular}

Table 8 Revised six-element model and error in the predicted strain after 7 days

\begin{tabular}{|l|l|c|l|}
\hline Combination & $\begin{array}{l}\text { Magnification } \\
n\end{array}$ & Equation & $\begin{array}{l}\text { Error in predicted strain after 7 } \\
\text { days (fused fabric) }\end{array}$ \\
\hline $1(\mathrm{~A}-\mathrm{a})$ & 0.208 & $\varepsilon=-0.170 e^{-0.487 t}-0.000916 e^{-0.797 t}+0.527$ & $-20.9 \%$ \\
\hline $2(\mathrm{~A}-\mathrm{b})$ & 0.210 & $\varepsilon=-0.104 e^{-0.257 t}-0.0895 e^{-0.542 t}+0.531$ & $-23.4 \%$ \\
\hline $3(\mathrm{~B}-\mathrm{a})$ & 0.300 & $\varepsilon=-0.277 e^{-0.487 t}-0.0255 e^{-0.643 t}+0.966$ & $-17.2 \%$ \\
\hline $4(\mathrm{~B}-\mathrm{b})$ & 0.280 & $\varepsilon=-0.277 e^{-0.517 t}-0.00205 e^{-0.808 t}+0.866$ & $-9.03 \%$ \\
\hline $5(\mathrm{C}-\mathrm{a})$ & 0.261 & $\varepsilon=-0.394 e^{-0.365 t}-0.0133 e^{-0.782 t}+1.175$ & $-14.8 \%$ \\
\hline $6(\mathrm{C}-\mathrm{b})$ & 0.227 & $\varepsilon=-0.304 e^{-0.236 t}-0.109 e^{-0.426 t}+1.045$ & $-15.8 \%$ \\
\hline
\end{tabular}

\section{Conclusion}

A creep test of woven fabrics, adhesive interlinings and their laminated combinations in the $45^{\circ}$ bias direction 
under low weight was carried out for 7 days. The test revealed creep of the samples even under only the fabric's own weight of a length of $80 \mathrm{~cm}$. Creep strain of the fused fabric was appreciably less than that of the overlapped fabric and that of the face fabric. The reduction of creep deformation in the bias direction due to adhesive interlining was thus confirmed. This is explained by the adhesive restraining deformation of the face fabric. This differs from creep behavior in the yarn direction [13].

The experimental creep strain of the face fabric and adhesive interlining could be predicted with a threeelement model. The creep behavior of overlapped fabrics was well approximated with a six-element model using parameters of the three-element model of component fabrics. This is the same result of creep behavior as for the yarn direction [14]. However, the creep behavior of a fused fabric could not be predicted with the six-element model because of the effect of adhesive. To take account of this effect in the six-element model, the three parameters of the model for the face fabric were multiplied by a factor $n$ so that the calculated strain and the experimental strain of the fused fabric agreed at time zero. The creep strains revised using the factor were in good agreement with the experimental strains of the fused fabric. The creep strains of laminated fabrics over 7 days could be predicted.

Consequently, if the experimental creep behavior of a face fabric and adhesive interlining and the strain of the fused fabric at time zero are obtained, the creep behavior of the fused fabric can be predicted using the six-element model. It will thus be possible to predict the effects of adhesive interlining in terms of maintaining clothing shape against deformation in the bias direction. The results are also useful for the selection of a suitable adhesive interlining in garment manufacturing.

\section{Acknowledgements}

This work was supported by JSPS KAKENHI under grant numbers JP24220012

\section{References}

[1] Ohtsuka M, Mitsuishi Y and Shimizu Y. Analysis of the hanging shape of the bias cut cloth. Sen'i Gakkaishi 2004; 60(5): 150-157.

[2] Takatera M, Kumoda N, Bao L, Shimizu Y, Kamijo M, Hosoya S and Iida H. Large deformation of woven fabrics under free shearing uni-axial load. Sen'i Gakkaishi 1999; 55(7): 306-314.

[3] Kumoda N, Hiraide M, Takatera M and Shimizu Y. Evaluation of heat set effect of woven fabrics under bias direction load. J Jpn Res Assoc Text End-uses 2001; 42(1): 51-59.

[4] Kim KO, Inui $S$ and Takatera $M$. Verification of prediction for bending rigidity of woven fabric laminated with interlining by adhesive bonding. Text Res J 2011; 81(6): 598-607.

[5] Kim KO, Inui $\mathrm{S}$ and Takatera $\mathrm{M}$. Prediction of bending rigidity for laminated fabric with adhesive interlining by a laminate model considering tensile and in-plane compressive moduli. Text Res J 2012; 82(4): 385-399.

[6] Kim K, Inui S and Takatera M. Bending rigidity of laminated fabric taking into account the neutral axes of components. Text Res J 2013; 83(2): 160-170.

[7] Kim K, Inui S and Takatera M. Prediction of bending rigidity for laminated weft knitted fabric with adhesive interlining. Text Res $J$ 2013; 83(9): 937-946.

[8] Kim KO and Takatera M. Effects of adhesive agent on shear stiffness of fabrics bonded with adhesive interlining. J Fiber Bioeng Inform 2012; 5(2): 151-162.

[9] Kim KO and Takatera M. Effects of dot-type adhesive and yarn float on shear stiffness of laminated fabric with interlining. Text Res $J$, in printing, 2015. doi: 10.1177/0040517515592812

[10] Deng M and Zhou J. Effects of temperature and stress level on creep and tensile property of polypropylene sutures. J Appl Polym Sci 2003; 90: 3882-3888.

[11] Nikolic MD and Mihailovic TV. Investigation of fabric deformations under different loading conditions. Int $J$ Cloth Sci Tech 1996; 8(4): 9-16.

[12] Asayesh A and Jeddi AAA. Modeling the creep behavior of plain woven fabrics constructed from textured polyester yarn. Text Res $J$ 2010; 80(7): 642-650.

[13] Urbelis V, Petrauskas A and Vitkauskas A. Time-dependent mechanical behaviour of heterogeneous textile fabric systems. Fibres Text Eastn Eur 2004; 12(4(48)): 37-42.

[14] Urbelis V, Petrauskas A and Vitkauskas A. Creep and creep recovery behaviour of textile fabrics and their fused systems. Mater Sci+ (Medžiagotyra) 2005; 11(2): 162-168.

[15] Urbelis V, Petrauskas A and Vitkauskas A. Study into the redistribution of tension on the components of the loaded textile fabric system. Fibres \& Textiles in Eastern Europe 2005; 13(4(52)): 38-42.

[16] Kim KO and Takatera M. Effects of adhesive agent on shear stiffness of fabrics bonded with adhesive interlining. J Fiber Bioeng Inform 2012; 5(2): 151-162.

[17] Yamamoto M. Zairyō kagaku no tame no buttai no henkei-gaku. Tokyo: Seibundo Shinkosha Publishing Co., Ltd., 1972, pp.150-163.

[18] Kawabata S. (1980) The standardization and analysis of hand evaluation. 2nd ed. Osaka: Textile Machinery Society of Japan. 